\title{
PENGARUH SOSIALISASI, PENERAPAN E-FILLING DAN TAX AMNESTY TERHADAP KEPATUHAN PAJAK (Studi Empiris Pada Wajib Pajak Orang Pribadi di KPP Pratama Kudus dan Pati)
}

\author{
Neneng Anjarwati ${ }^{1)}$, Febra Robiyanto ${ }^{2)}$ \\ Program Studi Akuntansi Fakultas Ekonomi dan Bisnis Universias Muria Kudus \\ ${ }^{1}$ Nanjarwati53@gmail.com \\ ${ }^{2}$ Febra.robiyanto@umk.ac.id
}

\begin{abstract}
ABSTRAK
Penelitian ini bertujuan untuk menganalisis pengaruh sosialisasi, penerapan e-Filling dan tax amnesty terhadap kepatuhan pajak pada wajib pajak orang pribadi (WPOP) di Kantor Pelayanan Pajak Pratama Kudus dan Pati. Penelitian ini menggunakan metode kuantitatif dengan menggunakan data primer yang diperoleh dari kuesioner. Populasi dalam penelitian ini dalah semua WPOP yang terdaftar di KPP Pratama Kudus dan Pati. Sampel dalam penelitian ini sebanyak 91 responden. Metode pengumpulan sampel menggunakan teknik accidental sampling. Metode analisis yang digunakan dalam penelitian ini yaitu uji validitas dan uji reliabilitas, uji normalitas, uji multikolineritas, uji heteroskedastisitas, uji regresi linier berganda, uji $\mathrm{F}$, uji t, uji independent sample t-test dan uji koefisien determinasi $\mathrm{R}^{2}$. Hasil pengujian menunjukkan bahwa sosialisasi tidak berpengaruh terhadap kepatuhan pajak WPOP, sedangkan penerapan e-Filling dan tax amnesty berpengaruh positif terhadap kepatuhan pajak WPOP.
\end{abstract}

Kata Kunci: sosialisasi, penerapan e-Filling, tax amnesty dan kepatuhan pajak.

\section{PENDAHULUAN}

Kantor Pelayanan Pajak (KPP) tidak asing lagi jika kita mendengar mengenai kasus ketidakpatuhan wajib pajak yang dilakukan oleh wajib pajak orang pribadi maupun wajib pajak badan. Kepatuhan wajib pajak yaitu perilaku seorang wajib pajak dalam melaksanakan semua kewajiban perpajakan dan menggunakan hak perpajakannya dengan tetap berpedoman pada peraturan perundang-undangan yang berlaku (Susmita dan Supadmi, 2016). Adanya isu mengenai rendahnya kepatuhan wajib pajak menjadi faktor yang sangat penting bagi negara karena secara tidak langsung akan mempengaruhi penerimaan pajak negara, sehingga akan berdampak pada kas negara.

Penerimaan pajak adalah penerimaan dalam negeri yang paling aman yang bersifat mudah menyesuaikan terhadap pendapatan negara, yang menjadi kunci dalam mengumpulkan data dan mencari informasi yang bermanfaat bagi pemerintah dalam mengatur perekonomian, yang mudah untuk dipengaruhi kondisinya daripada Penerimaan Negara Bukan Pajak (PNBP). 
Penerimaan pajak di Indonesia pada Januari 2015 mengalami penurunan dari yang ditargetkan Januari 2016. Penurunan ini disebabkan oleh menurunnya penerimaan dari minyak bumi dan gas alam. Berikut adalah daftar dari penerimaan pajak negara Indonesia pada Januari 2015 dan target pajak pada APBN Januari 2016. (Sumber : blogspot.co.id (Pajak, Penerimaan Pajak, Realisasi Penerimaan Pajak). Penelitian ini mereplikasi penelitian Susmita dan Supadmi, (2016). Adapun perbedaan penelitian ini dengan penelitian sebelumnya yaitu pertama, penelitian inimengganti dan menambahkan variabel independen yaitu sosialisasi dan tax amnesty. Kedua perbedaan pada objek penelitian yaitu di KPP Pratama Kudus dan Pati.

\section{KAJIAN PUSTAKA}

\section{Teori Rencanaan (Theory Of Planned Behavior)}

Theory Of Planned Behavior (TPB) atau teori perilaku rencanaan. Ajzen mengembangkan teori Theory Of Planned Behavior (TPB) dengan menambahkan sebuah konstruk yang belum ada di Theory Of Reasoned Action (TRA) pada tahun 1991. Konstruk ini disebut dengan kontrol perilaku persepsian (Perceived Behavioral Control). Konstruk ini ditambahkan di TPB untuk mengontrol perilaku individual yang dibatasi oleh kekurangankekurangan dan keterbatasan-keterbatasan dari kekurangan sumberdaya yang digunakan untuk melakukan perilakunya (Jogiyanto dan Abdilah, 2011:328). Sedangkan munculnya niat untuk berperilaku ditentukan berbagai faktor yaitu Behavioral Beliefs, Normative Beliefs, Control Beliefs.

\section{Pengertian Pajak}

Menurut Resmi (2014:18) mengacu pada undang-undang No. 28 Tahun 2007 pengertian pajak sebagai berikut: "Pajak adalah konstribusi wajib kepada negara yang terutang oleh wajib pajak pribadi atau badan yang sifatnya memaksa berdasarkan undang-undang dan tidak mendapatkan imbalan secara langsung digunakan untuk keperluan negara bagi sebesarbesarnya kemakmuran rakyat".

\section{Kepatuhan Wajib Pajak}

Kepatuhan wajib pajak yaitu wajib pajak yang taat dalam melaksanakan kewajibannya dengan pedoman sesuai dengan peraturan yang berlaku (Widowati, 2013). Jadi kepatuhan wajib pajak dapat diartikan sebagai bentuk patuhnya seseorang (wajib pajak) dalam menaati peraturan atau Undang-Undang perpajakan. 


\section{Sosialisasi}

Sosialisasi perpajakan yaitu upaya dari pihak Direktorat Jendral Pajak yang merupakan salah satu institusi di Kementerian Keuangan untuk memberikan pengertian, informasi, wawasan dan pembinaan kepada masyarakat pada umumnya dan wajib pajak pada khususnya mengenai segala sesuatu yang berhubungan dengan perpajakan perundang-undangan (Putri dan Pratomo, 2014)

\section{Penerapan E-Filling}

E-Filling adalah suatu cara penyampaian SPT secara elektronik yang dilakukan secara online dan real time melalui internet pada website Direktorat Jenderal Pajak (DJP) maupun Penyedia Jasa Aplikasi atau Aplication Sevice Provider (ASP) (Pandiangan, 2014:39). Wajib Pajak yang telah terdaftar sebagai wajib pajak e-Filling dapat melakukan pelaporan SPT tahunan dengan cara mengisi $e-S P T$ dengan benar, lengkap dan jelas kemudian meminta kode verifikasi pada DJP . Penyampian SPT secara online dapat dilakukan selama 7 hari, sehingga bermanfaat bagi wajib pajak yang sibuk bekerja sehingga tidak ada waktu untuk dating ke kantor pajak secara langsung.

\section{Tax Amnesty}

Tax amnesty merupakan penghapusan pajak yang seharusnya terutang dan tidak dikenakan sanksi admnistrasi perpajakan maupun sanksi pidana dibidang perpajakan, dengan menggunakan cara yaitu pengungkapan harta dan membayar sejumlah tebusan diatur dalam undang-undang no 11 tahun 2016 tentang pengampunan pajak (Rahayu, 2017). Kebijakan adanya tax amnesty bertujuan untuk meningkatkan pendapatan negara dan meningkatkan perekonomian negara serta meningkatkan kesadaran dan kepatuhan wajib pajak dalam melaksanakan kewajibannya dalam membayar pajak (Sari dan Fidiana, 2017).

\section{KERANGKA PEMIKIRAN}

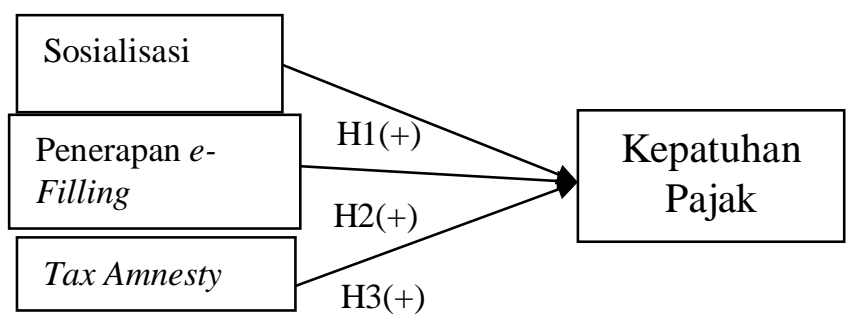

Sumber: Sari dan Fidiana (2016) yang telah di modifikasi.

Berikut adalah gambar kerangka pemikiran dari penelitian Sari dan Fidiana (2016) yang ditunjukkan pada Gambar 1.

Gambar 2.1

Kerangka Pemikiran 
Gambar 2.1 diatas adalah gambar kerangka pemikiran dari penelitian Sari dan Fidiana (2016)

\section{PENGEMBANGAN HIPOTESIS}

\section{Pengaruh Sosialisasi terhadap Kepatuhan Pajak}

Berdasarkan Theory Of Planned Behavior (TPB) sosialisasi dihubungkan dengan normative beliefs. Adanya sosialisasi perpajakan wajib pajak akan diberikan pengetahuan tentang seluruh peraturan perpajakan yang berlaku sehingga wajib pajak yang memiliki pengetahuan perpajakan akan memiliki motivasi untuk patuh dalam membayar pajak karena mereka sadar pentingnya membayar pajak.

Penelitian yang dilakukan Suryadi dan Sunarti (2016) membuktikan bahwa sosialisasi berpengaruh positif terhadap kepatuhan Pajak. Ada pun hipotesis yang diajukan dalam penelitian ini adalah:

$\mathrm{H}_{1}$ : Sosialisasi berpengaruh positif terhadap kepatuhan pajak.

\section{Pengaruh Penerapan e-Filling terhadap Kepatuhan Pajak}

Berdasarkan teori Theory Of Planned Behavioral (TPB) variabel e-Filling dihubungkan dengan normative beliefs. Adanya sistem e-Filling wajib pajak akan lebih dimudahkan dalam memenuhi kewajibannya karena dengan sistem tersebut wajib pajak tidak harus datang ke kantor pajak tetapi bisa melalui internet yang bisa dilakukan kapan saja. Penelitian yang dilakukan oleh Susmita dan Supadmi (2016) membuktikan bahwa penerapam e-Filling berpengaruh positif terhadap kepatuhan pajak. Ada pun hipotesis yang diajukan dalam penelitian ini adalah:

$\mathrm{H}_{2}$ : Penerapan $e$-Filling berpengaruh positif terhadap kepatuhan pajak.

\section{Pengaruh Tax Amnesty terhadap Kepatuhan Pajak}

Berdasarkan Theory Of Planned Behavior (TPB) variabel tax amnesty dihubungkan dengan normative beliefs. Adanya program tax amnesty, wajib pajak yang awalnya tidak melaksanakan kewajibannya dengan baik akan patuh dalam membayar pajak karena wajib pajak yang mengikuti program tax amnesty tidak dikenakan sanksi administrasi maupun sanksi pidana dengan melakukan pengungkapan harta dan membayar sejumlah tebusan. Penelitian yang dilakukan oleh Rahayu (2017) membuktikan bahwa tax amnesty berpengaruh positif terhadap terhadap kepatuhan pajak. Ada pun hipotesis yang diajukan dalam penelitian ini adalah:

$\mathrm{H}_{3}$ : Tax Amnesty berpengaruh positif terhadap kepatuhan pajak. 


\section{Apakah Terdapat Perbedaan Kepatuhan Pajak WPOP di KPP Pratama Kudus dan Pati}

Berdasarkan Theory Of Planned Behavior (TPB) variabel kepatuhan pajak dapat dihubungkan dengan normative belief. Kepatuhan pajak dengan sistem Self Asessement akan mendorong wajib pajak untuk patuh dalam melaksanakan kewajibannya. Kepatuhan pajak di KPP Pratama Kudus lebih rendah dari pada kepatuhan pajak di KPP Pati, karena Kudus wajib pajak masih banyak yang belum memahami hukum dan tata cara perpajakan sehingga wajib pajak cenderung malas untuk melaksanakan kewajibannya. Sedangkan di Pati sebagian besar wajib pajak sudah memahami hukum dan tata cara perpajakan sehingga kepatuhan pajak di Pati lebih patuh dari pada di Kudus.

$\mathrm{H}_{4}$ : Terdapat Perbedaan Kepatuhan Pajak WPOP di KPP Pratama Kudus dan Pati.

\section{METODE PENELITIAN}

Metode pendekatan kuantitatif yang bersifat asosiatif adalah metode yang digunakan untuk meneliti pada penelitian ini. Tempat penelitian di KPP Pratama Kudus dan Pati. Obyek yang diteliti adalah kepatuhan pelaporan WPOP di KPP Pratama Kudus dan Pati. Penelitian ini menggunakan data primer yang diperoleh dengan cara survey melalui penyebaran kuesioner. Teknik pengambilan sampel adalah accedintal. Sampel yang akan diteliti berjumlah 100 responden WPOP yang ditentukan dengan rumus slovin (Sugiyono, 2016:85). Teknik analisis data yang digunakan yakni uji instrumen penelitian. Menurut (Ghozali, 2011:19-53) uji instrumen penelitian terdiri dari uji validitas dan uji reliabilitas yang dilakukan untuk melihat apakah alat pengukuran dapat menghasilkan data yang relevan dan memberikan hasil yang tidak berbeda jika dilakukan pengujian kembali. Pengujian asumsi klasik yang dilakukan yaitu: uji normalitas, uji heteroskedastisitas, dan uji multikolinearitas. Pengaruh independen variabel terhadap dependen variabel dapat diketahui dengan melakukan analisis regresi linier berganda. Model analisis regresi linier berganda dirumuskan sebagai berikut:

$\mathrm{KP}=\alpha+\beta_{1} \mathrm{~S}+\beta_{2} \mathrm{SP}-\beta_{3} \mathrm{BK}+\beta_{4} \mathrm{PE}+\beta_{5} T A+\mathrm{e}$

\section{Keterangan:}

$$
\begin{array}{ll}
\mathrm{KP} & =\text { Kepatuhan pajak } \\
\alpha & =\text { Konstanta } \\
\beta 1-\beta 3 & =\text { Koefisien regresi } \\
\mathrm{S} & =\text { Sosialisasi } \\
\mathrm{PE} & =\text { Penerapan } e \text {-Filling }
\end{array}
$$


$\mathrm{T} A=$ Tax Amnesty

e $\quad=$ residual

\section{Pengukuran Variabel}

\section{Kepatuhan Pajak (Y)}

Menurut Susmita dan Supadmi (2016) kepatuhan pajak menggunakan 4 indikator yaitu: secara umum dapat dikatakan bahwa wajib pajak paham dan berusaha memahami Undang-Undang perpajakan, wajib pajak selalu mengisi formulir pajak dengan benar, wajib pajak selalu menghitung pajak dengan jumlah yang benar, wajib pajak selalu membayar pajak tepat pada waktunya.

\section{Sosialisasi $\left(\mathbf{X}_{1}\right)$}

Menurut Suherman (2013) sosialisasi menggunakan 5 indikator yaitu :saat peraturan baru, KPP setempat seminar, seminar penyuluhan, media cetak, televise, internet, spanduk, menambah pengetahuan.

\section{Penerapan E-Filling $\left(\mathbf{X}_{2}\right)$}

Menurut Susmita dan Supadmi (2016) e-Filling menggunakan 6 indikator yaitu:saat menggunakan e-Filling, wajib pajak dapat mengoperasikannya sesuai dengan kebutuhan, tampilan e-Filling mudah untuk dibaca sehingga wajib pajak mudah dalam memahaminya, adanya $e$-Filling dapat mempermudah pekerjaan wajib pajak, menggunakan e-Filling memungkinkan wajib pajak untuk mengerjakan tugas-tugas dengan lebih cepat, sistem $e$ Filling dapat membantu wajib pajak dalam melakukan pelaporan SPT tepat waktu, sistem $e$ Filling dapat membantu wajib pajak melakukan pelaporan secara efesien.

\section{Tax Amnesty $\left(\mathrm{X}_{3}\right)$}

Menurut Sari dan Fidiana (2017) tax amnesty menggunakan 5 indikator yaitu: wajib pajak mau berpartisipasi terhadap program tax amnesty, wajib pajak yang memiliki pemahaman senantiasa meningkatkan kepatuhan dalam melaksanakan kewajibannya, wajib pajak yang sadar akan adanya tax amnesty akan suka rela dalam membayar pajak, tax amnesty dapat digunakan sebagai alat transisi menuju sistem perpajakan yang baru, tax amnesty memiliki manfaat yang dapat meningkatkan penerimaan negara. 


\section{HASIL DAN PEMBAHASAN}

Data hasil kuesioner diperoleh gambaran responden yang dapat dilihat pada tabel 4.2 yaitu sebagai berikut:

Tabel 4.2

Profil Responden

$\begin{array}{lcc}\begin{array}{l}\text { Keterangan } \\ \text { Jenis Kelamin }\end{array} & \text { Jumlah } & \text { Presentase } \\ \text { Laki-laki } & 67 & 73,6 \% \\ \text { Perempuan } & 24 & 26,4 \% \\ \text { Umur Responden } & & \\ \text { <20 tahun } & 4 & 4,4 \% \\ \text { 21-30 tahun } & 35 & 38,5 \% \\ \text { 31-40 tahun } & 33 & 36,3 \% \\ & & \\ \text { 41-50ahun } & 19 & 20,9 \% \\ \text { >50 tahun } & 0 & 0 \% \\ \text { Pendidikan } & & \\ \text { SMA } & 19 & 20,9 \% \\ \text { S1 } & & \\ \text { S2 } & 15 & 16,5 \% \\ \text { Lainnya } & 30 & 33 \% \\ & & \end{array}$

Untuk memperjelas dan mempermudah pemahaman atas hasil penelitian ini, akan dideskripsikan statistik dari masing-masing variabel pada penelitian. Tabel 4.3 berikut ini akan menyajikan hasil analisis statistik deskriptif.

Tabel 4.3

Hasil Uji Statistik Deskriptif

\begin{tabular}{|l|c|c|c|c|c|}
\hline & $\mathrm{N}$ & Min & Max & Mean & $\begin{array}{c}\text { Std. } \\
\text { Deviation }\end{array}$ \\
\hline $\mathrm{S}$ & 91 & 20.00 & 45.00 & 33.527 & 5.898 \\
\hline $\mathrm{P} E$ & 91 & 19.00 & 30.00 & 25.109 & 3.361 \\
\hline$T A$ & 91 & 16.00 & 25.00 & 21.429 & 2.809 \\
\hline KP & 91 & 14.00 & 20.00 & 17.044 & 2.206 \\
\hline
\end{tabular}

Sumber: Data primer yang diolah, 2018.

Berdasarkan tabel 4.9 hasil statistik deskriptif dari masing-masing varibael yang diteliti, 
sosialisasi memiliki nilai minimum sebesar 20 dan nilai besar maximum 45 . Nilai rata-rata (mean) sebesar 33.527 dengan standar deviasi sebesar 5.898. E-Filling memiliki nilai minimum sebesar 19 dan nilai maximum sebesar 30. Nilai rata-rata sebesar 25.109 dengan standar deviasi sebesar 3.361. Tax amnesty memiliki nilai minimum sebesar 16 dan nilai maximum sebesar 25. Nilai rata-rata sebesar 21.429 dengan standar deviasi sebesar 2.809. Kepatuhan pajak memiliki nilai minimum sebesar 14 dan nilai maximum sebesar 20. Nilai rata-rata sebesar 17.044 dengan standar deviasi 2.206.

Hasil uji validitas sosialisasi, penerapan e-Filling, tax amnesty dan kepatuhan pajak memiliki nilai pearson correlation $>\mathrm{r}$ tabel yang telah ditetapkan yaitu $(\mathrm{df}=\mathrm{n}-2)$, sehingga masing-masing item dari variabel tersebut dinyatakan valid.

Tabel 4.4

Hasil Uji Reliabilitas

\begin{tabular}{|l|c|c|c|}
\hline & Pertanyaan & $\begin{array}{c}\text { Cronbach } \\
\text { Alpha }\end{array}$ & Keterangan \\
\hline $\mathrm{S}$ & 9 & 0,836 & Reliabel \\
\hline $\mathrm{P} E$ & 6 & 0,793 & Reliabel \\
\hline$T E$ & 5 & 0,707 & Reliabel \\
\hline $\mathrm{KP}$ & 4 & 0,701 & Reliabel \\
\hline
\end{tabular}

Sumber: Data primer yang diolah, 2018.

Berdasarkan tabel 4.4 diketahui bahwa semua item pertanyaan adalah reliabel karena dari masing-masing variabel tersebut memiliki nilai Cronbach Alpha > 0,70 maka reliabel.

Tabel 4.5

Hasil Uji Normalitas

\begin{tabular}{|c|c|c|}
\hline & $\begin{array}{c}\text { Unstandardized } \\
\text { Residual }\end{array}$ & Keterangan \\
\hline $\begin{array}{c}\text { Asymp. Sig (2- } \\
\text { tailed) }\end{array}$ & 0,200 & Normal \\
\hline
\end{tabular}

Sumber: Data primer yang diolah, 2018.

Hasil dari One-Sample Kolmogorov-Smirnov Test pada tabel 4.5 menunjukkan bahwa nilai Asymp.Sig (2-tailed) sebesar 0,200 > 0,05 maka data berdistribusi normal.

Tabel 4.6

Hasil Uji Mulitikolinieritas

\begin{tabular}{|l|c|c|c|}
\hline Variabel & $\begin{array}{c}\text { Toleranc } \\
\boldsymbol{e}\end{array}$ & VIF & Keterangan \\
\hline Sosialisasi & 0,960 & 1,041 & Bebas Multikolinieritas \\
\hline $\begin{array}{l}\text { Penerapan } \\
\text { e-Filling }\end{array}$ & 0,261 & 3,835 & Bebas Multikolinieritas \\
\hline $\begin{array}{l}\text { Tax } \\
\text { Amnesty }\end{array}$ & 0,256 & 3,911 & Bebas Multikolinieritas \\
\hline
\end{tabular}

Sumber: Data primer yang diolah, 2018. 


\section{[ACCOUNTING GLOBAL JOURNAL]

Berdasarkan tabel 4.6 hasil uji multikolinieritas menunjukkan tidak terjadi multikoliniieritas. Hal tersebut dapat diketahui adanya nilai tolerance $>0,1$ dan nilai VIF < 10 .

Tabel 4.7

Hasil Uji Heteroskedastisitas

\begin{tabular}{|l|c|c|c|}
\hline \multicolumn{1}{|c|}{ Varibael } & t Hitung & Sig & Keterangan \\
\hline Sosialisasi & 1,257 & 0,212 & Bebas Heteroskedastiistas \\
\hline Penerapan e-Filling & $-0,336$ & 0,737 & Bebas Heteroskedastisitas \\
\hline Tax Amnetsy & $-0,217$ & 0,828 & Bebas Heteroskedatisitas \\
\hline
\end{tabular}

Sumber: Data primer yang diolah, 2018.

Berdasarkan hasil uji heteroskedastisitas dengan menggunakan uji glejser pada tabel 4.7 menunjukkan bahwa semua variabel tidak mengandung adanya heteroskedastisitas karena data menunjukkan hasil nilai signifikansinya $>0,05$.

Tabel 4.8

Hasil Analisis Regresi Linier Berganda

\begin{tabular}{|l|c|c|c|c|c|}
\hline & \multicolumn{2}{|c|}{$\begin{array}{c}\text { Unstandardized } \\
\text { Coefficients }\end{array}$} & $\begin{array}{c}\text { Standardized } \\
\text { oefficients }\end{array}$ & \multirow{2}{*}{ Sig } & \\
\cline { 2 - 4 } & B & Std.Error & Beta & & \\
\hline $\begin{array}{l}\text { (Costant } \\
)\end{array}$ & 0,680 & 0,809 & & 0,840 &, 403 \\
\hline S &, 013 &, 015 &, 035 & 0,854 &, 395 \\
\hline $\mathrm{P} E$ &, 191 &, 051 &, 291 & 3,747 &, 000 \\
\hline$T A$ &, 520 &, 062 &, 662 & 8,431 &, 000 \\
\hline
\end{tabular}

Sumber: Data primer yang diolah, 2018.

Berdasarkan persamaan regresi linier tersebut, maka dapat disimpulakan sebagai berikut:

\section{$\mathrm{KP}=0,680+0,013 \mathrm{~S}+\mathbf{0 , 1 9 1 P E}+\mathbf{0 , 5 2 0 T A}+\mathrm{e}$}

Sosialisasi (S) dengan nilai koefisien regresi bernilai positif sebesar 0,013 artinya setiap peningkatan sosialisasi akan meningkatkan kepatuhan pajak sebesar 1,3\%. Penerapan e-Filling $(\mathrm{PE})$ dengan nilai koefisien regresi bernilai positif sebesar 0,191 artinya setiap peningkatan penerapan $e$-Filling akan meningkatkan kepatuhan pajak sebesar 19,1\%. Tax amnesty (TA) dengan nilai koefisien regresi bernilai positif sebesar 0,520 artinya setiap peningkatan $\operatorname{tax}$ amnesty akan meningkatkan kepatuhan pajak sebesar $52 \%$.

Tabel 4.9

Hasil Analisis Uji F

\begin{tabular}{|l|c|c|c|c|c|}
\hline \multicolumn{1}{|c|}{ Model } & $\begin{array}{c}\text { Sum of } \\
\text { Square }\end{array}$ & Df & $\begin{array}{c}\text { Mean } \\
\text { Square }\end{array}$ & F & Sig. \\
\hline 1 Regression & 377,830 & 3 & 125,94 & 182,63 &, 000 \\
Residual & 59,994 & 87 & 3 & 6 & \\
Total & 437,824 & 90 &, 690 & & \\
\hline
\end{tabular}

Sumber: Data primer yang diolah, 2018. 


\section{[ACCOUNTING GLOBAL JOURNAL] E ISSN}

Berdasatkan uji $F$ pada tabel 4.9 menunjukkan $F_{\text {hitung }}>F_{\text {tabel }}(182,636>2,32)$ dengan tingkat signifikan $0,000<0,05$. Dapat ditarik kesimpulan bahwa seluruh variabel independen secara simultan (bersama-sama) berpengaruh terhadap variabel dependen.

Tabel 4.10

Hasil Analisis Uji t

\begin{tabular}{|l|c|c|l|}
\hline Variabel & T & Signifikan & Keterangan \\
\hline (Constant) & 0,840 &, 403 & \\
\hline Sosialisasi & 0,854 &, 395 & Tidak Signifikan \\
\hline Penerapan e-Filling & 3,747 &, 000 & Signifikan \\
\hline Tax Amnesty & 8,431 &, 000 & Signifikan \\
\hline
\end{tabular}

Sumber: Data primer yang diolah, 2018.

Berdasarkan pengujian hipotesis pertama (H1) menunjukkan bahwa sosialisasi memiliki nilai signifikansi $0,395>0,05$ yang menunjukkan bahwa sosialisasi tidak berpengaruh terhadap kepatuhan pajak. Adanya sosialisasi perpajakan wajib pajak akan diberikan pengetahuan tentang seluruh peraturan perpajakan yang berlaku, tetapi wajib pajak yang diberikan sosialisasi tentang pengetahuan perpajakan belum tentu memiliki motivasi untuk patuh dalam membayar pajak karena ketika diberikan pengetahuan tentang perpajakan wajib pajak tetap datang tetapi tidak memperhatikan dengan baik karena dianggap membuang waktunya sehingga akan berdampak pada wajib pajak sendiri yaitu wajib pajak semakin tidak sadar akan pentingnya membayar pajak. Jadi semakin tinggi tingkat sosialisasi belum tentu mendorong wajib pajak untuk melaksanakan kewajibannya. Penelitian ini selaras dengan penelitian yang dilakukan oleh Winerungan (2013) menunjukkan bahwa sosialisasi perpajakan tidak berpengaruh terhadap kepatuhan wajib pajak. .

Berdasarkan hasil pengujian hipotesis kedua $\left(\mathrm{H}_{2}\right)$ menunjukkan e-Filling memiliki nilai signifikansi $0,000<0,05$ yang menunjukkan bahwa penerapan $e$-Filling berpengaruh positif terhadap kepatuhan pajak. Adanya sistem e-Filling wajib pajak akan semakin dimudahkan dalam memenuhi kewajibannya. Wajib pajak yang puas akan pelayanan sistem tersebut akan memiliki motivasi untuk patuh dalam melaksanakan kewajibannya dalam melaporkan SPT tahunan. Penelitian ini selaras dengan penelitian yang dilakukan oleh Susmita dan Supadmi (2016) menunjukkan bahwa penerapan e-Filling berpengaruh positif terhadap kepatuhan wajib pajak.

Berdasarkan pengujian hipotesis ketiga $\left(\mathrm{H}_{3}\right)$ menunjukkan tax amnesty memiliki nilai signifikansi $0,000<\alpha$ 0,05 yang menunjukkan bahwa tax amnesty berpengaruh positif terhadap kepatuhan pajak. Jadi semakin tinggi program tax amnesty wajib pajak akan semakin 


\section{[ACCOUNTING GLOBAL JOURNAL]

patuh dalam melaksanakan kewajibannya. Adanya program tax amnesty wajib pajak akan memiliki motivasi untuk melaksanakan kewajibannya dengan baik yang akan meningkatkan kepatuhan pajak. Penelitian ini selaras dengan penelitian yang dilakukan oleh Rahayu (2017) menunjukkan bahwa tax amnesty berpengaruh positif dan signifikan terhadap kepatuhan wajib pajak.

Tabel 4.11

Hasil Uji Independen Sample T-Test

\begin{tabular}{|c|c|c|c|c|c|}
\hline & Group & N & Mean & $\begin{array}{c}\text { Std. } \\
\text { Deviation }\end{array}$ & $\begin{array}{c}\text { Sig. } \\
\text { (2- } \\
\text { tailed) }\end{array}$ \\
\hline $\begin{array}{c}\text { Kepatuhan } \\
\text { Pajak }\end{array}$ & Kudus & 47 & 17,1064 & 2,13902 & 0,782 \\
\cline { 2 - 6 } & Pati & 44 & 16,9773 & 2,29751 & 0,782 \\
\hline
\end{tabular}

Sumber: Data primer yang diolah, 2018.

Berdasarkan hasil pengujian independent sample t-tes pada tabel 4.11 diperoleh nilai signifikansi ( $p$-value $)>\alpha=0,05$ maka dapat diambil kesimpulan bahwa dari kedua grup tidak menunjukkan adanya perbedaan.

Tabel 4.12

Hasil Uji Koefisien Determinasi $\left(\mathbf{R}^{2}\right)$

\begin{tabular}{|c|c|c|c|c|}
\hline Model & $\mathbf{R}$ & $\begin{array}{c}\boldsymbol{R} \\
\text { Square }\end{array}$ & $\begin{array}{c}\text { Adjusted } \boldsymbol{R} \\
\text { Square }\end{array}$ & $\begin{array}{c}\text { Std Error of the } \\
\text { Estimate }\end{array}$ \\
\hline 1 &, $929^{\mathrm{a}}$ &, 863 &, 858 &, 83041 \\
\hline
\end{tabular}

Sumber: Data primer yang diolah, 2018.

Berdasarkan tabel 4.12 diatas menunjukkan nilai adjusted $R$ Square sebesar 0,858 menunjukkan bahwa variabel independen secara simultan memberikan pengaruh sebesar $85,8 \%$ terhadap variabel dependen, sedangkan sisanya 14,2\% dipengaruhi oleh variabel lain yang tidak diteliti dalam penelitian ini.

\section{Kesimpulan}

Pengaruh sosialisasi terhadap kepatuhan pajak diperoleh nilai signifikansi sebesar 0,395 $>\alpha 0,05$ sehingga $\mathrm{H}_{1}$ ditolak, artinya sosialisasi tidak berpengaruh terhadap kepatuhan pajak. Hal ini menunjukkan bahwa semakin tinggi tingkat sosialisasi tidak mempengaruhi kepatuhan pajak.

Pengaruh penerapan e-Filling terhadap kepatuhan pajak diperoleh nilai signifikansi sebesar $0,000<\alpha 0,05$ sehingga $\mathrm{H}_{2}$ diterima, artinya penerapan e-Filling berpengaruh positif terhadap kepatuhan pajak. Hal ini menunjukkan bahwa semakin tinggi dalam penerapan 
sistem $e$-Filling maka wajib pajak akan semakin dimudahkan dan wajib pajak merasa puas maka akan patuh dalam melaksanakan kewajibannya.

Pengaruh tax amnesty terhadap kepatuhan pajak diperoleh nilai signifikansi sebesar $0,000<\alpha 0,05$ sehingga $\mathrm{H}_{3}$ diterima, artinya tax amnesty berpengaruh positif terhadap kepatuhan pajak. Hal ini menunjukkan bahwa semakin tinggi tingkat program tax amnesty maka wajib pajak merasa semakin diuntungkan dan wajib pajak akan lebih patuh dalam melaksanakan kewajibannya.

Berdasarkan pengujian independent sample t-test kepatuhan pajak antara KPP Kudus dan Pati diperoleh nilai signifikansi sebesar 0,782 Kudus dan 0,782 Pati yaitu sama-sama > 0,05 sehingga $\mathrm{H}_{6}$ diterima, artinya tidak terdapat perbedaan kepatuhan pajak antara Kudus dan Pati.

\section{Keterbatasan}

Penelitian ini menggunakan metode survey melalui penyebaran kuesioner, tanpa adanya wawancara karena untuk mempersingkat waktu. Variabel sosialisasi dalam penelitian ini hanya mengunakan indikator saat peraturan baru, Kantor Pelayanan Pajak (KPP) setempat seminar, seminar penyuluhan, media cetak, televisi, internet, spanduk, menambah pengetahuan., sehingga belum dapat digunakan dalam menentukan kepatuhan pajak dengan didapatkanya hasil yang tidak signifikan.

\section{Saran}

Bagi peneliti selanjutnya tidak hanya menggunakan metode kuesioner namun dapat menambahkan metode interview secara langsung kepada responden agar responden memberi jawaban yang benar-benar diliputi kesungguhan dan keseriusan. Penelitian selanjutnya dapat menambahkan indikator lain dalam variabel sosialisasi yaitu penyuluhan, diskusi dengan wajib pajak dan tokoh masyarakat, informasi langsung dari petugas ke wajib pajak pemasangan billboard, web site Ditjen pajak. Hal ini sesuai dengan penelitian yang dilakukan Winerungan (2013). 


\section{DAFTAR PUSTAKA}

Budiawan, Anthony. 2016. Pajak, Penerimaan Pajak, Realisasi Penerimaan Pajak. (http://anthonybudiawan.blogspot.co.id/?view=magazine, diakses 16 Januari 2018).

Ghozali, Imam. 2011. Aplikasi Analisis Multivariate dengan Program IBM SPSS19. Semarang : Badan Penerbit Universitas Diponegoro, Semarang.

Jogiyanto dan Willy, Abdillah. 2011. Sistem Tata Kelola Teknologi Informasi: Andi Offset, Yogyakarta.

Lidya, Winerungan Oktavianie. 2013. Sosialisasi Perpajakan, Pelayanan Fiskus dan Sanksi Perpajakan Terhadap Kepatuhan WPOP Di KPP Manado Dan KPP Bitung. Jurnal EMBA. Vol. 1 No. 3. Universitas Sam Ratulangi Manado.

Pandiangan, Liberti. 2014. Administrasi Perpajakan: Jakarta: Erlangga.

Putri, Dwi Purnama dan Dudi, Pratomo. 2014. Pengaruh Sosialisasi Perpajakan, Dan Help Desk Terhadap Kepatuhan Wajib Pajak. Vol. 1 No. 3. Jurnal e-Proceeding of Management. Universitas Telkom.

Rahayu, Nurulita. 2017. Pengaruh Pengetahuan Perpajakan, Ketegasan Sanksi Pajak, Dan Tax Amnesty Terhadap Kepatuhan Wajib Pajak. Akuntansi Dewantara. Jurnal Akuntansi Dewantara. Vol. 1 No. 1. Universitas Sarjanawiyata.

Rara, Susmita Putu dan Ni Luh, Supadmi. 2016. Pengaruh Kualitas Pelayanan, Sanksi Perpajakan, Biaya Kepatuhan Pajak, Dan Penerapan E-Filling Pada Kepatuhan Wajib Pajak. E-Jurnal Akuntansi. Vol. 14 No. 2. Universitas Udayana.

Resmi, Siti. 2014. Perpajakan: Edisi 8 Buku 1, Jakarta: Salemba Empat.

Sari, Viega Ayu Permata dan Fidiana. 2017. Pengaruh Tax Amnesty, Pengetahuan Perpajakan, Dan Pelayanan Fiskus Terhadap Kepatuhan Wajib Pajak. Jurnal Ilmu Dan Riset Akuntansi. Vol. 6 No. 2. STIESIA Surabaya.

Sugiyono. 2016. Metode Penelitian. Cetakan Ke-23, Penerbit Cv. Alfabeta, Bandung.

Suherman, Rudi. 2013. "Pengaruh Sosialisasi Perpajakan dan Penerapan Self Asssesment System Terhadap Kepatuhan Wajib Pajak Orang Pribadi Pada KPP Pratama Pasar Rebo". Skripsi. Universitas Muhammadiyah Prof. Dr. Hamka.

Suyadi, Imam dan Sunarti. 2016. Pengaruh Sosialisasi Perpajakan, Sanksi Admnistrasi dan Tingkat Pemahaman Wajib Pajak Terhadap Tingkat Kepatuhan Wajib Pajak Orang Pribadi Dalam Memenuhi Kewajibannya. Junal Perpajakan. Vol. 8 No. 1. Universitas Brawijaya. Undang-Undang Republik Indonesia No. 11 Tahun 2016 Tentang Pengampunan Pajak. 2018. Jakarta: HukumOnline.com. 2016.

Widowati, Rizky. 2015. "Kepatuhan Wajib Pajak Melalui Sosialisasi Perpajakan, Sanksi Perpajakan, Pengetahuan Pajak dan Pelayanan Fiskus". Skripsi. Universitas Dian Nuswantoro Semarang. 